\title{
FIM DA DICOTOMIA RURAL-URBANO? um olhar sobre os processos socioespaciais
}

\author{
Aurílio Sérgio Costa Caiado \\ Sarah Maria Monteiro dos Santos
}

\begin{abstract}
Resumo: O artigo discute alguns processos socioespaciais em curso em municípios do Estado de São Paulo, tais como a conurbação, metropolização e a expansão da ocupação urbana em áreas oficialmente definidas como rurais, para mostrar que não existe mais a velha dicotomia urbano-rural e que a definição oficial do IBGE não mais dá conta de explicar a diversidade de usos, carecendo de redefinição.

Palavras-chave: política urbana; urbanização; rural-urbano.

Abstract: This article discusses some of the socio-spatial processes underway in the cities of the State of São Paulo, such as conurbation, metropolitanization and the expansion of urban occupation in areas officially defined as rural, to demonstrate that the old rural-urban dichotomy is no longer valid and that the official IGBE definition no longer explains the diversity of usages, and is in need of being re-elaborated.

Key words: urban policy; urbanization; rural-urban.
\end{abstract}

$\mathrm{P}$ ara procurar avançar na discussão das definições de rural e urbano, com vistas à análise do desenvolvimento regional, parte-se do princípio que os conceitos formais de rural e urbano, baseados nos limites administrativos (lei do perímetro urbano), já não são suficientes para explicar os complexos processos socioeconômicos e socioespaciais em curso no Estado de São Paulo.

Nas últimas décadas, a principal característica das transformações socioespaciais é o crescimento da conurbação em aglomerações metropolitanas ou não-metropolitanas, concentrando parcela crescente da população. Por outro lado, o fenômeno de redução do peso das atividades agrícolas no emprego e na renda das pessoas que habitam o meio rural, que tem sido registrado em países desenvolvidos, apresenta tendência crescente em São Paulo.

Com vistas a reunir informações sobre o crescente processo de transformação e diversificação das espacialidades presentes no Estado de São Paulo, analisam-se informações coletadas pela Pesquisa Municipal Unificada da Fundação Seade - PMU/1999, ${ }^{1}$ em todos os municípios paulistas, sobre a existência de ocupações urbanas em áreas rurais, tais como: loteamentos sem aprovação, loteamentos aprovados por lei especial, grandes equipamentos de lazer e indústrias, e sobre processos de conurbação com outros municípios. A análise desses dados segundo informações sobre legislações municipais, mostra a extensão do fenômeno no Estado e faz refletir sobre a necessidade de buscar novos instrumentais de análise que representem a complexa realidade de uma sociedade urbana, cada vez mais metropolitana. Para tanto o artigo está dividido em três itens. O primeiro discute as principais características da rede urbana paulista e a redução do peso das atividades agrícolas na área rural. O segundo apresenta os resultados da PMU/1999 sobre a existência de ocupações urbanas em áreas rurais e o terceiro traz alguns comentários finais.

\section{A REDE URBANA PAULISTA}

A rede de cidades do Estado de São Paulo é a mais complexa do país. Sua constituição remonta ao século XIX, quando, a partir do dinamismo econômico impulsionado pelo complexo cafeeiro, o território passou por processo contínuo e permanente de ocupação (Caiado, 1995).

O recorte tradicional usado em estudos sobre urbanização, que partia da dicotomia existente entre cidade e cam- 
po (moderno e atrasado) e estudava a rede urbana paulista distinguindo a área metropolitana da capital do restante do Estado - denominado interior -, não consegue mais explicar os diversos processos de integração produtiva, funcional e física em curso fora da Região Metropolitana de São Paulo. Esta continua sendo a principal metrópole do país e a principal cidade mundial da América do Sul, pelas articulações econômicas com os demais centros nacionais e com as principais metrópoles internacionais. Entretanto, no que diz respeito ao padrão de urbanização vigente no Estado, com a interiorização do desenvolvimento, as realidades territoriais tornaram-se mais complexas, engendrando formações espaciais que refletem o caráter contraditório do dinamismo econômico.

As maiores cidades do interior estão localizadas nas regiões mais industrializadas e de maior desenvolvimento, demonstrando a relação entre a dinâmica populacional e o crescimento econômico no Estado de São Paulo. A localização das atividades econômicas e da população privilegiou as sedes regionais e/ou seus entornos imediatos, notadamente as Regiões Administrativas de Campinas, Santos, Sorocaba, São José dos Campos e Ribeirão Preto, fortalecendo o papel daqueles centros na rede urbana estadual e levando para o interior um padrão de urbanização até então vigente somente na metrópole. ${ }^{2}$

A estruturação e a ampliação do mercado imobiliário, articulado e organizado em suas diversas etapas de reprodução do capital mercantil (parcelamento, construção, incorporação, financiamento e vendas), ampliaram o processo de verticalização das cidades, com a construção de residências multifamiliares e de edifícios de escritórios. Favoreceram, também, o surgimento dos condomínios fechados horizontais para a classe média, de bairros periféricos sem infra-estrutura urbana e favelas em quase todas as cidades do interior, independentemente de seu porte, expressões visíveis desse padrão contraditório de urbanização. Esse processo expressa-se em uma dinâmica socioespacial que se repete nas diversas realidades territoriais como ambientes construídos pelo capital e para o capital.

A principal característica da rede urbana estadual, nas últimas décadas, é a conurbação, produzindo aglomerações metropolitanas ou não-metropolitanas e concentrando parcela crescente da população. ${ }^{3}$ Além da grande diversidade e da alta densidade de centros, apresenta as interações espaciais mais intensas e complexas de todo o país. Isso se reflete em padrões espaciais que variam segundo as especificidades das diferentes regiões do Estado e compreendem, nas suas escalas superiores: ${ }^{4}$
- metrópoles de caráter mundial, nacional e regional;

- aglomerações urbanas que se desenvolveram a partir de um núcleo;

- aglomerações urbanas constituídas de centros urbanos com complementaridade funcional, que dividem as funções polarizadoras e, espacialmente, se articulam com alguma contigüidade, muitas vezes ao longo de eixos viários;

- aglomerações urbanas constituídas por centros urbanos que dividem as funções polarizadoras sem possuir contigüidade espacial, formando um conjunto de cidades articuladas;

- centros urbanos que polarizam sozinhos os municípios de seu entorno desempenhando o papel de centro regional.

Essas espacialidades nem sempre são perfeitamente identificáveis ou passíveis de serem isoladas, dada a complexidade da rede e as múltiplas inter-relações. Em regiões mais dinâmicas e de maior densidade de centros, as relações socioeconômicas se dão segundo diferentes vetores, fazendo com que as articulações, quer de subordinação quer de complementaridade, aconteçam entre centros de diferentes aglomerações. Isso é facilmente evidenciado nos municípios próximos da RMSP. Além da forte atração exercida por aquela metrópole, os processos de conurbação e integração produtiva existentes na região de Jundiaí, por exemplo, e sua articulação com municípios da Região Metropolitana de Campinas - RMC e da Aglomeração Urbana de Sorocaba dificultam o estudo e a delimitação da aglomeração. $\mathrm{O}$ mesmo pode ser dito em relação às Aglomerações Urbanas de São José dos Campos, de Sorocaba e de Guaratinguetá.

O crescimento urbano tem ampliado a divisão de funções urbanas entre algumas cidades e a atração que alguns centros exercem sobre o território. A existência de três áreas metropolitanas, onze aglomerações urbanas e várias cidades de porte médio são a face de uma estrutura territorial, cuja contraface está no grande número de municípios com população urbana inferior a 20 mil habitantes.

É um Estado urbano, com $75 \%$ da população residindo em regiões metropolitanas ou em aglomerações urbanas. No conjunto as RMs e AUs tiveram crescimento médio anual de 1,9\%, entre 1991 e 2000, acima, portanto, da média estadual.

A rede de cidades paulistas se estrutura em subsistemas que se constituíram vis-à-vis os processos econômicos das regiões onde se localizam e que possuem características diversificadas. Fortemente polarizada pela capital, a Região Metropolitana de São Paulo - RMSP é a princi- 
pal metrópole e, a despeito do processo de diminuição de seu ritmo de crescimento, continuava abarcando em 2000 quase metade da população estadual, 17.852 mil habitantes $(48,3 \%)$.

As outras principais aglomerações estão situadas no entorno da metrópole paulistana, principalmente ao longo de quatro eixos principais a partir da capital:

- o eixo Anhangüera/Bandeirantes em direção ao interior, passando por Campinas, indo até Ribeirão Preto;

- o eixo formado pelas rodovias Carvalho Pinto/Presidente Dutra que liga São Paulo ao Vale do Paraíba;

- aquele formado pelas rodovias Castelo Branco e Raposo Tavares, que articula as cidades da Região de Sorocaba; e

- as rodovias Anchieta e Imigrantes, que ligam a capital à Baixada Santista.

A Região Metropolitana da Baixada Santista-RMBS, instituída pela Lei Complementar $n^{\circ} 815 / 96$, tem 1.473 mil habitantes $(4,0 \%)$ e a Região Metropolitana de Campinas - RMC, instituída pela Lei Complementar $n^{\circ} 870$ / 2000, 2.332 mil habitantes (6,3\%).

As três regiões metropolitanas juntas abrigam 58,6\% da população estadual (21.659 mil hab.) e tiveram taxa média anual de crescimento de $1,81 \%$ entre 1991 e 2000 , praticamente igual à média estadual $(1,82 \%)$. A única RM que cresceu abaixo da média estadual foi a RMSP (1,68\%). As outras - RMBS e RMC - tiveram taxa média de crescimento demográfico superior à média estadual $(2,17 \% \mathrm{e}$
$2,59 \%$, respectivamente) e ampliaram suas participações no total da população estadual (Tabelas 1 e 2).

As 11 aglomerações urbanas existentes, envolvendo 58 municípios, tiveram crescimento médio de $2,2 \%$ e somente as AUs de Araçatuba e Guaratinguetá tiveram crescimento abaixo da média estadual $(1,7 \%$ e $1,2 \%$, respectivamente) entre 1991 e $2000^{5}$ (Tabela 2).

Os demais municípios paulistas não pertencentes às aglomerações urbanas (RMs ou AUs), num total de 520 municípios, tiveram crescimento abaixo da média estadual (1,6\%). Desse conjunto, os pequenos, com população até 20 mil habitantes, que somam 396 municípios e abrigam $7,7 \%$ da população estadual, tiveram taxa negativa de crescimento (-0,5 a.a.) com perda populacional de 144 mil habitantes, entre 1991 e 2000. Aqueles com população entre 20 mil e 50 mil (86 municípios) cresceram a uma taxa média equivalente à média estadual, $1,8 \%$ a.a. Os na faixa entre 50 mil e 100 mil habitantes (27 municípios) tiveram crescimento médio medíocre, de $0,5 \%$ a.a., entretanto essa taxa é explicada pela mudança de faixa de vários municípios que passaram a ter mais de 100 mil habitantes em 2000. Isso explica, também, a elevada taxa de crescimento dos municípios com população de mais de 100 mil habitantes, em 2000 (7,5\% a.a.).

Em síntese, há forte concentração demográfica em áreas urbanas de maior complexidade (RMs e AUs) ou em municípios isolados considerados pólos regionais. ${ }^{6}$ Cabe salientar que nas regiões metropolitanas as sedes tiveram

TABELA 1

Rede Urbana- Síntese

Estado de São Paulo - 1991-2000

\begin{tabular}{|c|c|c|c|c|c|c|}
\hline \multirow{2}{*}{ Rede Urbana } & \multirow{2}{*}{$\begin{array}{c}\text { Número de } \\
\text { Municípios } \\
(2000)\end{array}$} & \multicolumn{2}{|c|}{ População EstimadaTotal } & \multirow{2}{*}{$\begin{array}{c}\text { Taxa Média } \\
\text { Anual } \\
1991 / 2000\end{array}$} & \multicolumn{2}{|c|}{ Distribuição } \\
\hline & & 1991 & 2000 & & 1991 & 2000 \\
\hline Regiões Metropolitanas & 67 & 18.437 .098 & 21.659 .537 & 1,8 & 58,6 & 58,6 \\
\hline Aglomerações Urbanas & 58 & 5.124 .364 & 6.254 .044 & 2,2 & 16,3 & 16,9 \\
\hline Demais Municípios & 520 & 7.874 .811 & 9.060 .797 & 1,6 & 25,1 & 24,5 \\
\hline \multicolumn{7}{|c|}{ Municípios Isolados por Faixa de Tamanho } \\
\hline Até 5 mil Habitantes & 179 & 602.832 & 577.031 & $-0,5$ & 1,9 & 1,6 \\
\hline De 5 a 10 mil Habitantes & 111 & 818.396 & 788.021 & $-0,4$ & 2,6 & 2,1 \\
\hline De 10 a 20 mil Habitantes & 106 & 1.572 .708 & 1.484 .541 & $-0,6$ & 5,0 & 4,0 \\
\hline De 20 a 50 mil Habitantes & 86 & 2.212 .397 & 2.600 .029 & 1,8 & 7,0 & 7,0 \\
\hline De 50 a 100 mil Habitantes & 27 & 1.733 .091 & 1.818 .775 & 0,5 & 5,5 & 4,9 \\
\hline De 100 a 250 mil Habitantes & 9 & 657.998 & 1.176 .596 & 6,7 & 2,1 & 3,2 \\
\hline Mais de 250 mil Habitantes & 2 & 277.389 & 615.804 & 9,3 & 0,9 & 1,7 \\
\hline
\end{tabular}

Fonte: IBGE; Fundação Seade. 
TABELA 2

Rede Urbana

Estado de São Paulo - 1991-2000

\begin{tabular}{|c|c|c|c|c|c|c|}
\hline \multirow{2}{*}{ Rede Urbana } & \multirow{2}{*}{$\begin{array}{l}\text { Número de } \\
\text { Municípios } \\
(2000)\end{array}$} & \multicolumn{2}{|c|}{ População EstimadaTotal } & \multirow{2}{*}{$\begin{array}{l}\text { Taxa Média } \\
\text { Anual } \\
1991 / 2000\end{array}$} & \multicolumn{2}{|c|}{ Distribuição } \\
\hline & & 1991 & 2000 & & 1991 & 2000 \\
\hline ESTADO DE SÃO PAULO & 645 & 31.436 .273 & 36.974 .378 & 1,8 & 100,0 & 100,0 \\
\hline Região Metropolitana de São Paulo & 39 & 15.369 .305 & 17.852 .637 & 1,7 & 48,9 & 48,3 \\
\hline São Paulo & & 9.610 .659 & 10.426 .384 & 0,9 & 30,6 & 28,2 \\
\hline Demais Municípios & & 5.758 .646 & 7.426 .253 & 2,9 & 18,3 & 20,1 \\
\hline Região Metropolitana de Campinas & 19 & 1.852 .813 & 2.332 .988 & 2,6 & 5,9 & 6,3 \\
\hline Campinas & & 843.516 & 968.160 & 1,5 & 2,7 & 2,6 \\
\hline Demais Municípios & & 1.009 .297 & 1.364 .828 & 3,4 & 3,2 & 3,7 \\
\hline Região Metropolitana da Baixada Santista & 9 & 1.214 .980 & 1.473 .912 & 2,2 & 3,9 & 4,0 \\
\hline Santos & & 417.114 & 417.975 & 0,0 & 1,3 & 1,1 \\
\hline Demais Municípios & & 797.866 & 1.055 .937 & 3,2 & 2,5 & 2,9 \\
\hline Aglomeração Urbana de São José dos Campos & 6 & 1.002 .477 & 1.209 .640 & 2,1 & 3,2 & 3,3 \\
\hline São José dos Campos & & 439.231 & 538.298 & 2,3 & 1,4 & 1,5 \\
\hline Demais Municípios & & 563.246 & 671.342 & 2,0 & 1,8 & 1,8 \\
\hline Aglomeração Urbana de Ribeirão Preto & 9 & 615.390 & 739.857 & 2,1 & 2,0 & 2,0 \\
\hline Ribeirão Preto & & 428.377 & 504.162 & 1,8 & 1,4 & 1,4 \\
\hline Demais Municipios & & 187.013 & 235.695 & 2,6 & 0,6 & 0,6 \\
\hline Aglomeração Urbana de Sorocaba & 10 & 813.202 & 1.040 .967 & 2,8 & 2,6 & 2,8 \\
\hline Sorocaba & & 376.513 & 492.245 & 3,0 & 1,2 & 1,3 \\
\hline Demais Municípios & & 436.689 & 548.722 & 2,6 & 1,4 & 1,5 \\
\hline Aglomeração Urbana de Jundiaí & 6 & 453.917 & 561.931 & 2,4 & 1,4 & 1,5 \\
\hline Jundiaí & & 288.228 & 323.056 & 1,3 & 0,9 & 0,9 \\
\hline Demais Municípios & & 165.689 & 238.875 & 4,1 & 0,5 & 0,6 \\
\hline Aglomeração Urbana de São José do Rio Preto & 3 & 324.251 & 417.413 & 2,8 & 1,0 & 1,1 \\
\hline São José do Rio Preto & & 279.507 & 357.705 & 2,8 & 0,9 & 1,0 \\
\hline Demais Municípios & & 44.744 & 59.708 & 3,3 & 0,1 & 0,2 \\
\hline Aglomeração Urbana de Araraquara/São Carlos & 5 & 358.911 & 433.576 & 2,1 & 1,1 & 1,2 \\
\hline Araraquara & & 158.934 & 182.240 & 1,5 & 0,5 & 0,5 \\
\hline São Carlos & & 157.549 & 192.639 & 2,3 & 0,5 & 0,5 \\
\hline Demais Municípios & & 42.428 & 58.697 & 3,7 & 0,1 & 0,2 \\
\hline Aglomeração Urbana de Araçatuba & 2 & 226.699 & 263.185 & 1,7 & 0,7 & 0,7 \\
\hline Araçatuba & & 152.018 & 169.087 & 1,2 & 0,5 & 0,5 \\
\hline Demais Municípios & & 74.681 & 94.098 & 2,6 & 0,2 & 0,3 \\
\hline Aglomeração Urbana de Bauru & 4 & 365.880 & 439.455 & 2,1 & 1,2 & 1,2 \\
\hline Bauru & & 259.504 & 315.493 & 2,2 & 0,8 & 0,9 \\
\hline Demais Municípios & & 106.376 & 123.962 & 1,7 & 0,3 & 0,3 \\
\hline Aglomeração Urbana de Limeira/Rio Claro & 6 & 523.436 & 634.235 & 2,2 & 1,7 & 1,7 \\
\hline Limeira & & 206.456 & 248.618 & 2,1 & 0,7 & 0,7 \\
\hline Rio Claro & & 137.041 & 167.902 & 2,3 & 0,4 & 0,5 \\
\hline Demais Municípios & & 179.939 & 217.715 & 2,1 & 0,6 & 0,6 \\
\hline Aglomeração Urbana de Guaratinguetá & 3 & 195.488 & 216.903 & 1,2 & 0,6 & 0,6 \\
\hline Guaratinguetá & & 92.077 & 104.101 & 1,4 & 0,3 & 0,3 \\
\hline Demais Municípios & & 103.411 & 112.802 & 1,0 & 0,3 & 0,3 \\
\hline Aglomeração Urbana de Mogi Guaçu/Moji Mirim & 4 & 244.713 & 296.882 & 2,2 & 0,8 & 0,8 \\
\hline Mogi Guaçu & & 100.237 & 123.984 & 2,4 & 0,3 & 0,3 \\
\hline Moji Mirim & & 64.523 & 81.293 & 2,6 & 0,2 & 0,2 \\
\hline Demais Municípios & & 79.953 & 91.605 & 1,5 & 0,3 & 0,2 \\
\hline Municípios Não Pertencentes a RMs ou AUs & 520 & 7.874 .811 & 9.060 .797 & 1,6 & 25,1 & 24,5 \\
\hline
\end{tabular}

Fonte: IBGE; Fundação Seade. 
crescimento baixo (São Paulo e Campinas) ou nulo (Santos), mas os demais municípios metropolitanos cresceram acima da média estadual, inclusive na RMSP.

É importante destacar que não só as áreas urbanas têm mudado suas feições. No que diz respeito à área rural, a agropecuária paulista é predominantemente de alto padrão tecnológico, com um expressivo segmento moderno, responsável por uma parcela significativa da produção de lavouras comerciais que demandam cada vez menos trabalhadores, e cujo perfil exigido é diferente do tradicional "homem do campo" e com algum nível de instrução. Também persiste, em algumas regiões, uma agropecuária tradicional e de baixo padrão tecnológico.

Entretanto, apenas as tradicionais atividades produtivas agrícolas e pecuárias não conseguem mais explicar a dinâmica do emprego e da população rural do Estado. É preciso incluir outras variáveis rurais não-agrícolas, decorrentes da crescente urbanização do meio rural, tais como: hospedagem, turismo, lazer e outros serviços, atividades de preservação do meio ambiente, além de um conjunto de atividades intensivas em mão-de-obra, como olericultura, floricultura, fruticultura de mesa, piscicultura e criação de pequenos animais (rãs, canários, aves exóticas, etc.) que buscam "nichos de mercado" específicos (Graziano da Silva, 1999; Balsadi; Borin; Julio, 2001).

Do total de pessoas ocupadas com residência rural, mais de $50 \%$ já estavam ocupadas em atividades não-agrícolas em 1999. Chama a atenção o ritmo desse processo nos anos 90, pois entre 1992 e 1997 houve uma clara inversão a favor do emprego rural não-agrícola no Estado de São Paulo. $^{7}$

Houve redução no número de pessoas ocupadas em atividades agrícolas no Estado, de 1.211 mil, em 1992, para 927 mil, em 1999. O total de pessoas com domicílio rural e ocupado em atividades não-agrícolas em 1999 era de 472 mil, superando o total ocupado em atividades agrícolas (455 mil pessoas).$^{8}$

As principais dinâmicas que influenciam o crescimento de ocupações não-agrícolas no meio rural podem ser resumidas da seguinte forma:

- atividades vinculadas à produção agropecuária, principalmente a produção direta de bens e serviços agropecuários, e a indireta, relacionada com sua comercialização, processamento e transporte;

- atividades derivadas do consumo da população rural, que incluem a produção de bens e de serviços não-agropecuários, tanto de origem rural quanto urbana e os serviços auxiliares a eles relacionados;
- atividades derivadas da disponibilidade de mão-de-obra excedente no meio rural, que inclui o trabalho em domicílio e o trabalho complementar daqueles que exercem outra atividade não-agrícola remunerada;

- expansão dos serviços públicos no meio rural;

- demanda por terras para uso não-agrícola pelas (agro) indústrias e empresas prestadoras de serviços;

- demanda da população urbana de baixa renda por terrenos para autoconstrução de suas moradias em áreas rurais situadas nas proximidades das cidades;

- demanda da população urbana de alta renda por áreas de lazer e/ou segunda residência, bem como pelos serviços a elas relacionados;

- consumo não-agrícola da população urbana, que é constituído por bens e serviços realizados no meio rural (artesanato, turismo ecológico, etc.);

- "novas atividades agropecuárias", que buscam nichos de mercado.

Em resumo, já não se pode caracterizar o meio rural paulista somente como agrário. O comportamento do emprego no meio rural não pode mais ser explicado apenas a partir do calendário agrícola e da expansão/retração das áreas e/ou produção agropecuárias. Há um conjunto de atividades não-agrícolas que responde, cada vez mais, pela nova dinâmica populacional do meio rural paulista.

\section{OCUPAÇÃO URBANA EM ÁREA RURAL NOS MUNICÍPIOS PAULISTAS}

As diferenças na caracterização das áreas urbanas e rurais nos diversos países do mundo fazem com que não exista uma definição de população urbana aplicável a todos. As definições nacionais de população urbana são mais comumente baseadas no tamanho da localidade. A população rural está sendo definida por exclusão: aquela que não habita as áreas urbanas (United Nations Statistics Division, 2002).

$\mathrm{Na}$ América Latina, para os 20 maiores países, ${ }^{9}$ cerca de $35 \%$ utilizam o tamanho da localidade como parâmetro na definição de população urbana, sendo que o tamanho mínimo varia de 1.500 a 2.500 habitantes. Alguns países acrescentam a esse parâmetro a existência de serviços ou outras características urbanas. Cerca de 30\% utilizam a categoria de sede de municípios e/ou de distritos; e outros utilizam leis para a definição da área urbana.

Verifica-se que de 1960 até os dias atuais muitos países alteraram sua definição de população urbana para efeito dos censos demográficos, quer acrescentando caracterís- 
ticas específicas, qualificadoras do espaço urbano, quer aumentando a exigência de aglomeração (população mínima), chegando-se em alguns casos a definições complexas e com muitas exceções. ${ }^{10}$

O desenvolvimento mundial e a urbanização crescente das populações resultam nessa complexidade presente na atualidade para a identificação do rural e do urbano.

No Brasil, cabe ao município definir o limite oficial entre as zonas urbanas e zonas rurais de seu território através da Lei de Perímetro Urbano.

Em 1999, 67,1\% dos municípios brasileiros possuíam Lei de Perímetro Urbano, a lei mais encontrada em nossos municípios (Bremaeker, 2001). Para o Estado de São Paulo esse percentual era de 57\% em 1992 e passou a $65 \%$ em 1999, segundo dados da PMU/Seade.

Analisando as datas das leis de perímetro urbano, informadas pelas prefeituras paulistas, verifica-se a sua pequena incidência até o final da década de 70, quando da aprovação da Lei Lhemam $\left(n^{\circ} 6.766 / 79\right) .{ }^{11} \mathrm{Na}$ década de 80 , o número de municípios que aprovaram leis de perímetro urbano cresceu e, na década de 90, esse número triplicou. Isso ocorreu paralelamente à expansão das áreas urbanizadas, freqüentemente sem controle, das municipalidades. As leis vieram muitas vezes a reboque do processo (Gráfico 1).

Com efeito, o crescimento desordenado de nossas cidades vem acontecendo em muitos municípios através de uma expansão que extrapola os limites urbanos definidos por lei, avançando sobre áreas rurais em detrimento da produção agrícola e algumas vezes com conseqüências negativas para o meio ambiente. Essa expansão tem ocorrido tanto por meio de loteamentos populares que expandem as periferias com urbanização precária, quanto através de condomínios de alto padrão destinados à população com alto poder aquisitivo, que busca melhor qualidade de vida em áreas menos densas e afastadas dos centros urbanos.

Cerca de um terço dos municípios paulistas afirmaram possuir algum tipo de ocupação urbana em área rural em seus territórios, em 1999. Para 75\% dos maiores municípios, população superior a 500 mil habitantes, a resposta foi afirmativa; para aqueles com população entre 50 mil e 500 mil esse percentual é de 45\% (Tabela 3 ).

O tipo mais freqüente de ocupação urbana em área rural é o loteamento sem aprovação da prefeitura, observado em $19 \%$ dos municípios paulistas, num total de 1.051 loteamentos nessa situação em todo o Estado. A incidência é de $75 \%$ nos grandes municípios, está entre $23 \%$ e $35 \%$ nos municípios com população entre 50 mil e 500 mil habitantes, e é de $12 \%$ nos pequenos municípios (população inferior a 5 mil habitantes).

Existem ainda, localizados em área rural, cerca de 300 loteamentos aprovados por legislação especial em todo Estado, situados em 12\% dos municípios. As maiores incidências estão nos municípios das faixas de população

GRÁFICO 1

Número de Municípios, segundo Lei de Perímetro Urbano

Estado de São Paulo - 1970-99

№ de Municípios

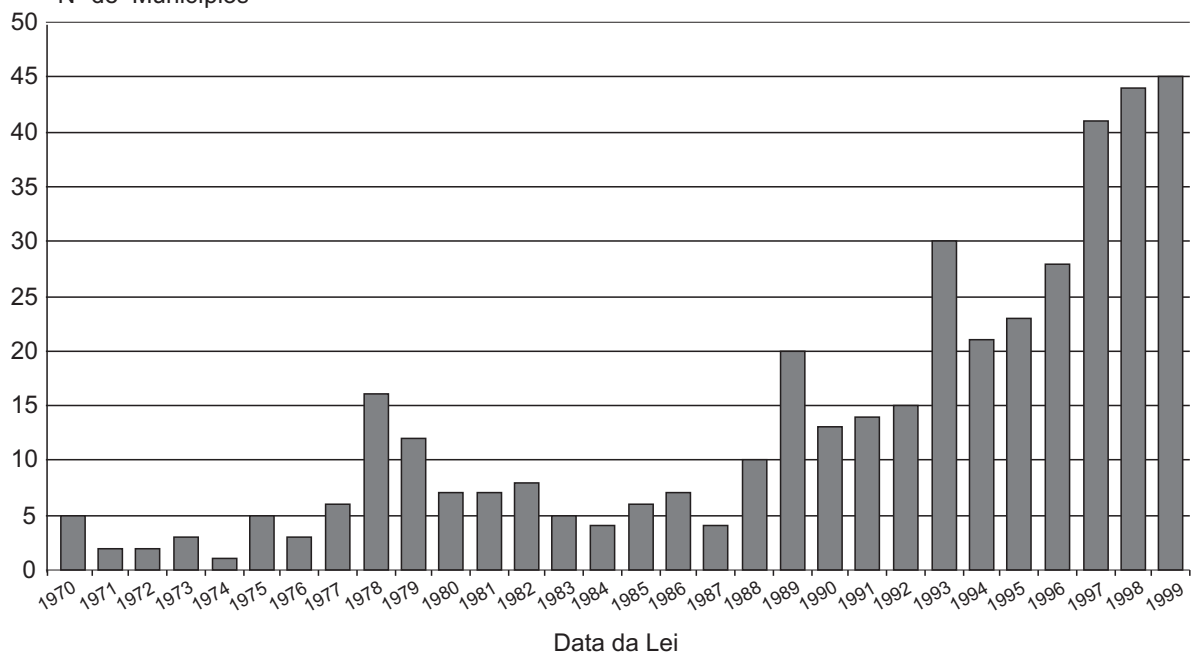

Fonte: Fundação Seade. PMU/1999 


\begin{tabular}{|c|c|c|c|c|c|c|c|c|c|}
\hline \multicolumn{10}{|c|}{$\begin{array}{l}\frac{\text { TABELA 3 }}{\text { Ocupação Urbana em Área Rural }} \\
\text { Estado de São Paulo - } 1999\end{array}$} \\
\hline Tipologia & Total & Até 5 Mil & $\begin{array}{l}\text { Mais de } \\
5 \text { Mil } \\
\text { a } 10 \text { Mil }\end{array}$ & $\begin{array}{l}\text { Mais de } \\
10 \mathrm{Mil} \\
\text { a } 20 \mathrm{Mil}\end{array}$ & $\begin{array}{l}\text { Mais de } \\
20 \mathrm{Mil} \\
\text { a } 50 \mathrm{Mil}\end{array}$ & $\begin{array}{l}\text { Mais de } \\
50 \text { Mil } \\
\text { a } 100 \text { Mil }\end{array}$ & $\begin{array}{l}\text { Mais de } \\
100 \text { Mil } \\
\text { a } 250 \text { Mil }\end{array}$ & $\begin{array}{l}\text { Mais de } \\
250 \text { Mil } \\
\text { a } 500 \text { Mil }\end{array}$ & $\begin{array}{l}\text { Mais de } \\
500 \text { Mil }\end{array}$ \\
\hline Número de Municípios & 645 & 180 & 116 & 117 & 117 & 53 & 40 & 14 & 8 \\
\hline \multicolumn{10}{|c|}{ Ocupação Urbana em Área Rural } \\
\hline Possui & 211 & 36 & 39 & 40 & 42 & 24 & 20 & 4 & 6 \\
\hline \multicolumn{10}{|c|}{ Loteamentos sem Aprovação } \\
\hline Possui & 123 & 21 & 21 & 26 & 19 & 12 & 14 & 4 & 6 \\
\hline \multicolumn{10}{|c|}{ Loteamentos de Lei Especial } \\
\hline Possui & 74 & 13 & 10 & 16 & 20 & 5 & 7 & 2 & 1 \\
\hline $\begin{array}{l}\% \\
\text { Indústria }\end{array}$ & 11,5 & 7,2 & 8,6 & 13,7 & 17,1 & 9,4 & 17,5 & 14,3 & 12,5 \\
\hline Possui & 75 & 8 & 14 & 11 & 18 & 10 & 10 & 2 & 2 \\
\hline$\%$ & 11,6 & 4,4 & 12,1 & 9,4 & 15,4 & 18,9 & 25 & 14,3 & 25 \\
\hline \multicolumn{10}{|l|}{ Lazer } \\
\hline Possui & 36 & 7 & 3 & 6 & 9 & 7 & 2 & 1 & 1 \\
\hline$\%$ & 5,6 & 3,9 & 2,6 & 5,1 & 7,7 & 13,2 & 5,0 & 7,1 & 12,5 \\
\hline
\end{tabular}

Fonte: Fundação Seade. PMU/1999.

de 20 mil a 50 mil habitantes e de 100 mil a 250 mil habitantes (17\% dos municípios, em cada grupo).

Por outro lado, $12 \%$ dos municípios afirmaram possuir indústrias em área rural, não sendo possível no entanto identificar o tipo de indústria, se agroindústria ou não.

A distribuição regional mostra uma ligeira concentração do fenômeno na região mais urbanizada do Estado, mas também a presença nas demais regiões paulistas. Verificase que mais de $60 \%$ dos municípios de Regiões de Governo próximas à metrópole paulistana declararam possuir ocupações urbanas em área rural. São elas as Regiões de Governo - RG de São José dos Campos e Taubaté, pertencentes à Região Administrativa - RA de São José dos Campos; na RG de Sorocaba, pertencente à RA de Sorocaba; nas RGs de Campinas, Jundiaí e Bragança Paulista, da RA de Campinas; e na RG de Jaú, da RA de Bauru. Do conjunto de 42 RGs paulistas, apenas nas RGs de Caraguatatuba no litoral e de Dracena no extremo noroeste não existem ocorrências de ocupações urbanas em área rural.

Na RA de São José dos Campos, a maior parte das ocupações diz respeito a loteamentos sem aprovação. O maior número de loteamentos sem aprovação está na RG de São José dos Campos, seguida da RG de Sorocaba. A RA de São José dos Campos, seguida da RA de Campinas, re- gistra o maior número de indústrias localizadas em área rural.

No caso da RG de Jaú as ocorrências se dividem entre indústrias e loteamentos aprovados por lei especial, com apenas um caso de loteamento sem aprovação.

Em apenas sete das 42 regiões de governo paulistas não se registram loteamentos sem aprovação localizados em área rural: Caraguatatuba, Rio Claro, São João da Boa Vista, Lins, Jales, Votuporanga, Dracena e Tupã.

Para os loteamentos aprovados por lei especial, o maior número é observado na RA de Campinas, seguida da RA de Sorocaba, não tendo sido registrado nenhum na RA de Marília e apenas um na RA de Santos.

Analisando a incidência da ocupação urbana em área rural vis-à-vis a rede urbana paulista, constata-se uma forte relação entre o número de eventos e a localização do município em regiões metropolitanas, aglomerações urbanas ou nos principais centros. Localizam-se nos $134 \mathrm{mu}-$ nicípios de maior hierarquia da rede, cerca de 64\% dos loteamentos sem aprovação, 76\% dos loteamentos aprovados por lei especial, $60 \%$ das indústrias localizadas em área rural e 56\% dos grandes equipamentos de lazer localizados fora dos perímetros urbanos municipais (Tabela 4 e Mapa 1). 
TABELA 4

Número de Ocupações Urbanas em Área Rural Estado de São Paulo - 1999

\begin{tabular}{|c|c|c|c|c|c|}
\hline $\begin{array}{l}\text { Regiões Metropolitanas, Aglomerações } \\
\text { e Centros Urbanos }\end{array}$ & $\begin{array}{l}\text { Número de } \\
\text { Municípios }\end{array}$ & $\begin{array}{l}\text { Número de Loteamentos } \\
\text { sem Aprovação }\end{array}$ & $\begin{array}{l}\text { Número de Loteamentos } \\
\text { Aprovados por Lei Especial }\end{array}$ & $\begin{array}{l}\text { Número } \\
\text { de Indústrias }\end{array}$ & $\begin{array}{l}\text { Equipamentos } \\
\text { de Lazer }\end{array}$ \\
\hline ESTADO DE SÃO PAULO & 645 & 1.051 & 1.270 & 289 & 74 \\
\hline Total das Regiões Metropolitanas & & 140 & 25 & 72 & 9 \\
\hline Região Metropolitana de São Paulo & 39 & 106 & 11 & 26 & 6 \\
\hline São Paulo & 1 & $\ldots$ & 6 & $\ldots$ & $\ldots$ \\
\hline Demais Municípios & 38 & $\ldots$ & 5 & $\ldots$ & $\ldots$ \\
\hline Região Metropolitana de Campinas & 19 & 29 & 13 & 45 & 3 \\
\hline Campinas & 1 & 17 & 0 & 0 & 0 \\
\hline Demais Municípios & 18 & 12 & 13 & 45 & 3 \\
\hline Região Metropolitana da Baixada Santista & 9 & 5 & 1 & 1 & 0 \\
\hline Santos & 1 & 0 & 0 & 0 & 0 \\
\hline Demais Municípios & 8 & 5 & 1 & 1 & 0 \\
\hline Total das Aglomerações Urbanas & & 453 & 939 & 94 & 7 \\
\hline Aglomeração Urbana de São J. dos Campos & 6 & 200 & 3 & 71 & 0 \\
\hline São José dos Campos & 1 & 141 & 0 & 22 & 0 \\
\hline Demais Municípios & 5 & 59 & 3 & 49 & 0 \\
\hline Aglomeração Urbana de Ribeirão Preto & 9 & 3 & 0 & 4 & 0 \\
\hline Ribeirão Preto & 1 & 2 & 0 & 0 & 0 \\
\hline Demais Municípios & 8 & 1 & 0 & 4 & 0 \\
\hline Aglomeração Urbana de Sorocaba & 10 & 66 & 4 & 5 & 1 \\
\hline Sorocaba & 1 & 3 & 3 & 4 & 0 \\
\hline Demais Municípios & 9 & 63 & 1 & 1 & 1 \\
\hline Aglomeração Urbana de Jundiaí & 6 & 78 & 912 & 2 & 0 \\
\hline Jundiaí & 1 & 56 & 11 & 0 & 0 \\
\hline Demais Municípios & 5 & 22 & 901 & 2 & 0 \\
\hline Aglomeração Urbana de São J. do Rio Preto & 3 & 100 & 0 & 0 & 2 \\
\hline São José do Rio Preto & 1 & 100 & 0 & $\ldots$ & 2 \\
\hline Demais Municípios & 2 & 0 & 0 & $\ldots$ & 0 \\
\hline Aglomeração Urbana de Araraquara/São Carlos & 5 & 2 & 10 & 0 & 0 \\
\hline Araraquara & 1 & 0 & 0 & 0 & 0 \\
\hline São Carlos & 1 & 2 & 10 & 0 & 0 \\
\hline Demais Municípios & 3 & 0 & 0 & 0 & 0 \\
\hline Aglomeração Urbana de Araçatuba & 2 & 4 & 0 & 0 & 0 \\
\hline Araçatuba & 1 & 4 & 0 & 0 & 0 \\
\hline Demais Municípios & 1 & 0 & 0 & 0 & 0 \\
\hline Aglomeração Urbana de Bauru & 4 & 0 & 0 & 0 & 0 \\
\hline Bauru & 1 & 0 & 0 & 0 & 0 \\
\hline Demais Municípios & 3 & 0 & 0 & 0 & 0 \\
\hline Aglomeração Urbana de Limeira/Rio Claro & 6 & 0 & 0 & 4 & 0 \\
\hline Limeira & 1 & $\ldots$ & 0 & 4 & 0 \\
\hline Rio Claro & 1 & 0 & $\ldots$ & $\ldots$ & 0 \\
\hline Demais Municípios & 4 & 0 & $\ldots$ & 0 & 0 \\
\hline Aglomeração Urbana de Guaratinguetá & 3 & 0 & 0 & 6 & 4 \\
\hline Guaratinguetá & 1 & 0 & 0 & 0 & 0 \\
\hline Demais Municípios & 2 & 0 & 0 & 6 & 4 \\
\hline Aglomeração Urbana de Mogi Guaçu/Moji Mirim & 4 & 0 & 10 & 2 & 0 \\
\hline Mogi Guaçu & 1 & $\ldots$ & 1 & 1 & 0 \\
\hline Moji Mirim & 1 & 0 & 6 & 1 & 0 \\
\hline Demais Municípios & 2 & 0 & 3 & 0 & 0 \\
\hline Total dos Centros Urbanos (1) & 9 & 76 & 6 & 7 & 0 \\
\hline Demais Municípios & 511 & 382 & 300 & 116 & 58 \\
\hline
\end{tabular}

Fonte: Fundação Seade. PMU/1999.

(1) Inclui os municípios de Botucatu, Bragança Paulista, Catanduva, Franca, Itapetininga, Jaú, Marilia, Piracicaba e Presidente Prudente. 


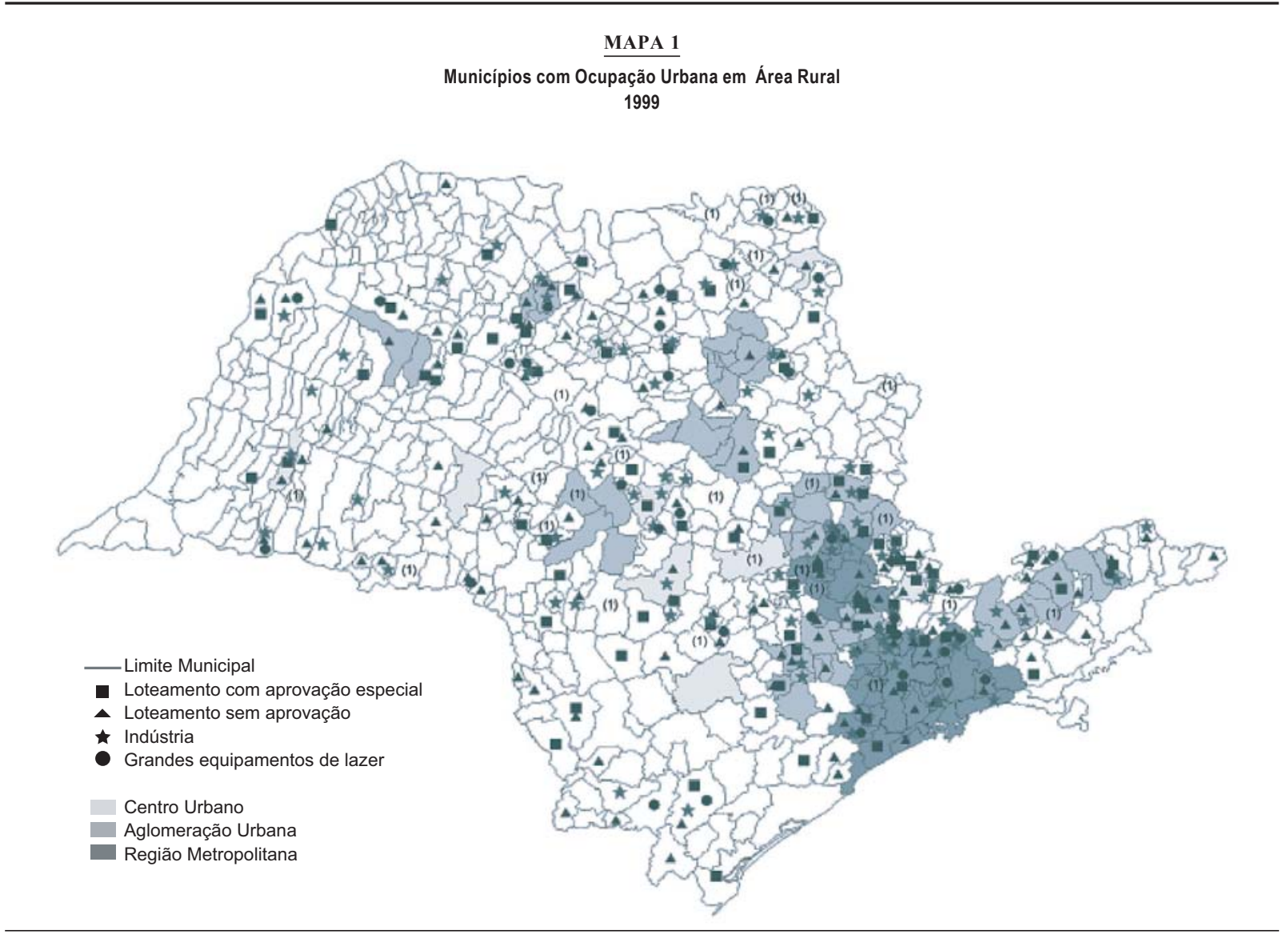

Fonte: Fundação Seade. PMU/1999

(1) Não respondeu à PMU/1999.

\section{CONSIDERAÇÕES FINAIS}

Analistas que estudam a dinâmica do setor agrícola têm chamado a atenção para a mudança de padrão do trabalho no campo, com o crescimento de atividades não-agrícolas. Para desenvolver seus estudos, reclassificam as informações estatísticas coletadas pelo IBGE, segundo local de moradia, para fugir da clássica divisão entre rural e urbano e, mesmo considerando rural somente os moradores que habitam em áreas isoladas, constatam a mudança do padrão e a existência de um novo rural (Projeto rurbano, 2002).

Este trabalho procurou analisar o outro lado da questão, ou seja: o avanço da ocupação tipicamente urbana em áreas oficialmente consideradas rurais. A conclusão a que chegamos é consentânea àquela da equipe do Projeto Rurbano e aponta para a necessidade de rediscutir os conceitos de área urbana e área rural, adotados pelo IBGE.

Além disso, pode-se dizer que uma das principais características da rede urbana paulista é o processo de conurbação, com formação de aglomerações urbanas e regiões metropolitanas. Nessas áreas registra-se com mais freqüência conurbações entre dois ou mais municípios, constituindo mancha urbana única, o que reforça o argumento da necessidade de se analisar e principalmente de constituir estruturas de planejamento para as aglomerações, tratandoas como espaço urbano único de interrelações complexas.

Por fim é importante alertar para a necessidade de o planejamento municipal abarcar todo o território do município e não somente a área considerada urbana, regulando o uso e a ocupação do solo no município de sorte a evitar o surgimento e expansão de ocupações ilegais, a margem do poder público. 


\section{NOTAS}

1. A PMU é uma pesquisa aplicada em todos os municípios paulistas desde 1992.

2. São consideradas sedes regionais as sedes das regiões administrativas. O Estado de São Paulo tem uma divisão administrativa em 15 regiões, sendo 14 Regiões Administrativas - RAs e a Região Metropolitana de São Paulo. As RAs são as seguintes: RA de Registro, RA de Santos, RA de São José dos Campos, RA de Campinas, RA de Sorocaba, RA de Ribeirão Preto, RA de Bauru, RA de Marília, RA de São José do Rio Preto, RA de Presidente Prudente, RA de Araçatuba, RA de Franca, RA de Barretos e RA Central. A Região Metropolitana da Baixada Santista coincide com a RA de Santos e a Região Metropolitana de Campinas compreende 19 dos 90 municípios da RA de Campinas.

3. Cerca de $11 \%$ dos 645 municípios paulistas apresentam-se conurbados, segundo a PMU/1999. O processo de conurbação é uma realidade consolidada nas Regiões Metropolitanas de São Paulo e de Campinas e nos eixos das Rodovias Anhangüera e Dutra. O tipo mais freqüente de conurbação é o da mancha urbana principal contínua em dois ou mais municípios, que ocorre em sete dos oito municípios com mais de 500 mil habitantes existentes no Estado, e em $43 \%$ dos municípios com população entre 250 mil e 500 mil habitantes. A conurbação do tipo mancha urbana de um município que extrapola para o município limítrofe está mais presente entre os municípios com população variando entre 100 mil e 500 mil habitantes.

4. Sobre os padrões espaciais da rede urbana paulista ver Caiado e Santos, 2001

5. As aglomerações urbanas estão assim distribuídas: três na RA de Campinas (AU de Limeira/Rio Claro e AU de Jundiaí, AU de Mogi Guaçu/Moji Mirim); duas na RA de São José dos Campos (AU de São José dos Campos e AU de Guaratinguetá); uma na RA de Sorocaba (AU de Sorocaba ), uma na RA de São José do Rio Preto (AU de São José do Rio Preto); uma na RA de Ribeirão Preto (AU de Ribeirão Preto); uma na RA Araçatuba (AU de Araçatuba), uma na RA Central (AU de Araraquara/São Carlos); uma na RA de Bauru (AU de Bauru).

6. Os principais Centros Urbanos Isolados têm a seguinte distribuição, por RA: Franca na RA de Franca; Piracicaba e Bragança Paulista na RA de Campinas; Itapetininga e Botucatu na RA de Sorocaba; Jaú na RA de Bauru; Catanduva na RA de São José do Rio Preto; e Presidente Prudente e Marília situadas em RAs de mesmo nome.

7. Do total de pessoas ocupadas na agricultura paulista, praticamente $50 \%$ têm residência urbana e $50 \%$, residência rural (ou seja, a queda do emprego também terá fortes efeitos nas cidades, onde reside boa parte dos trabalhadores rurais)

8. O número de pessoas ocupadas com domicílio rural teve uma queda de apenas $0,3 \%$ ao ano no período 1992-99, comportamento que só não foi pior devido ao excelente desempenho das atividades nãoagrícolas, que apresentaram crescimento de $6,1 \%$ ao ano no número de pessoas ocupadas, passando de 326 mil pessoas ocupadas, em 1992, para 472 mil, em 1999. O total de ocupados na agropecuária residentes no meio rural teve redução significativa de 5,0\% ao ano, valor próximo ao observado para aqueles com residência urbana $(4,9 \%$ ao ano).

Os principais ramos de atividade não-agrícola responsáveis pela ocupação da PEA rural foram: prestação de serviços, indústria de transformação, indústria da construção, comércio de mercadorias e serviços sociais. Em 1999, esses cinco ramos de atividade respondiam por $90 \%$ do total das ocupações não-agrícolas no interior.
9. Argentina, Bolívia, Brasil, Cuba, Chile, Colômbia, Costa Rica, Equador, El Salvador, Guatemala, Haiti, Honduras, México, Nicarágua, Panamá, Paraguai, Peru, República Dominicana, Uruguai, Venezuela.

10. Conforme informações do Centro Latinoamericano y Caribeño de Demografia - Celade/Cepal, Boletim Demográfico n.63 de janeiro de 1999, que traz as definições de população urbana e rural utilizadas nos censos demográfico de países da América Latina a partir de 1960.

11. Lei federal que discorre sobre o parcelamento do solo urbano e exprime a exigência da definição de perímetro urbano para a aplicação da mesma.

\section{REFERÊNCIAS BIBLIOGRÁFICAS}

BALSADI, O.V.; BORIN, M.R.; JULIO, J.E. A agropecuária paulista. São Paulo: Fundação Seade, 2001. Mimeografado.

BREMAEKER, F.E.J. Os instrumentos de gestão urbana dos municípios para a aplicação do Estatuto da Cidade. Ibam, 2001.

CAIADO, A.S.C. Dinâmica socioespacial e a rede urbana paulista. São Paulo em Perspectiva, São Paulo, Fundação Seade, v.9, n.3, p.4653, jul./set. 1995.

CAIADO, A.S.C.; SANTOS, S.M.M. Novas espacialidades na rede urbana paulista. In: IX ENCONTRO NACIONAL DA ANPUR. Anais... Rio de Janeiro, 2001.

CANO, W. Raízes da concentração industrial em São Paulo. São Paulo: Hucitec, 1990

CENTRO LATINOAMERICANO Y CARIBEÑO DE DEMOGRAFIA (Celade/Cepal). Boletin Demográfico n.63, enero 1999.

GRAZIANO DA SILVA, J.F. O novo rural brasileiro. Campinas: Unicamp - Instituto de Economia, 1999. (Coleção Pesquisa, 1).

IPEA/UNICAMP.IE.NESUR/IBGE (Org.). Caracterização e tendências da rede urbana do Brasil. Campinas, SP: Unicamp - Instituto de Economia, 1999 (Coleção Pesquisas, 3).

KAGEYAMA, A.; LEONE, E. Uma tipologia dos municípios paulistas com base em indicadores sociodemográficos. Textos para discussão, n.66, IE/Unicamp, 1999.

NEGRI, B. Concentração e desconcentração industrial em São Paulo. Tese (Doutorado) - Instituto de Economia da Unicamp, Campinas, 1994

PACHECO, C.A. Fragmentação da nação. Campinas: Unicamp - Instituto de Economia, 1998

PROJETO RURBANO. Disponível em: < http://www.eco.unicamp.br/ projetos/rurbano/rurbanw.html>. Acesso em: 13 out. 2002

UNITED NATIONS STATISTICS DIVISION. Disponível em: $<$ http://www.millenniumindicators.un.org $>$. Acesso em: $12 \mathrm{dez}$. 2002 .

Aurílio Sérgio Costa Caiado: Arquiteto, Analista da Fundação Seade e Professor da Universidade de Sorocaba.

Sarah Maria Monteiro dos SAntos: Engenheira-Urbanista, Analista da Fundação Seade. 